\title{
Prevention of further bone mass loss by nasal calcitonin in patients on long term glucocorticoid therapy for asthma: a two year follow up study
}

\author{
Maite Luengo, Francesca Pons, Mariá J Martinez de Osaba, César Picado
}

\begin{abstract}
Background - Injectable calcitonin is effective in reducing spinal bone loss in steroid-dependent asthma but side effects are frequent. In contrast, a nasal spray presentation has been shown to be effective and well tolerated in involutional osteoporosis. To test the efficacy of nasal calcitonin a two year prospective trial was conducted in 44 steroid-dependent asthmatic patients.
\end{abstract}

Methods - All patients received a calcium supplement of $1000 \mathrm{mg}$ and were allocated randomly into two groups treated with either salmon calcitonin nasal spray (200 IU every other day, $n=22$ ) or calcium alone $(n=22)$ for two years. All patients completed the first year of the study. Five patients in each group dropped out during the second year. In the calcitonin group one patient developed generalised pruritus and four lost steroid dependence, and in the calcium alone group five were no longer dependent on steroids. The efficacy of treatment was evaluated as follows: bone turnover assessed by biochemical markers, bone loss assessed by serial measurement of lumbar spine density, and rates of bone fractures.

Results - The bone mass in the calcitonin group increased by $2 \cdot 7 \%$ in the first year while in the group receiving calcium alone it decreased by $2 \cdot 8 \%$; this difference was significant. Calcitonin prevented more bone loss during the second year while the calcium alone group continued losing bone mass $(-7 \cdot 8 \%)$. The difference between means was $0.1077(95 \%$ CI 0.0381 to $0 \cdot 1773)$. Three new fractures occurred in both groups. No changes in biochemical parameters were detected in either group. Conclusions - Calcitonin given intranasally increased spinal bone mass during the first year of treatment and maintained bone mass in a steady state during the second year. These results suggest that calcitonin may be a useful agent to prevent steroid-induced osteoporosis. However, the lack of effect of calcitonin on the rate of vertebral fractures does not permit its recommendation for routine use in preventing steroid-induced osteoporosis.

(Thorax 1994;49:1099-1102)
Osteoporosis is the most disabling side effect of prolonged, oral glucocorticoid therapy. Corticosteroids increase bone resorption and also depress bone formation, perhaps through a decrease in osteoblast activity associated with a decrease of vitamin $\mathrm{D}$ receptors. ${ }^{12}$ Different strategies are currently being investigated to prevent the development of steroid-induced osteoporosis including inhibitors of bone resorption and stimulators of bone formation. Bone formation may be stimulated by anabolic steroids ${ }^{3}$ while resorption can be inhibited by bisphosphonates ${ }^{4}$ or calcitonin. ${ }^{5}$ In a previous study we have shown that injectable calcitonin can be effective in reducing spinal bone loss in chronic steroid-dependent asthma. ${ }^{5}$ With this formulation, however, side effects were frequent and represented a serious inconvenience for prolonged treatment. In contrast to the parenteral route, a nasal spray presentation has been shown to be well tolerated and effective in involutional osteoporosis. ${ }^{6}$ To test the efficacy and tolerability of nasal calcitonin in steroid-dependent asthma we conducted a 24month prospective trial in a group of adult asthmatic patients receiving long term oral glucocorticoid treatment.

\section{Methods}

\section{PATIENTS}

Forty four consecutive glucocorticoid-dependent asthmatic patients were recruited from outpatients. Those receiving drugs (hormones, diuretics, vitamin $\mathrm{D}$, and anticonvulsants) or suffering from diseases known to affect bone metabolism were excluded. The patients had all received oral glucocorticoids for at least one year. All patients were non-smokers, led a sedentary life, and none drank more than $20 \mathrm{~g}$ ethanol/day. Patients eligible for the study who gave informed consent were grouped according to sex and age (a difference within two years was accepted) and randomly assigned to receive either salmon calcitonin nasal spray (200 IU every day) (Sandoz, Barcelona, Spain) and $1 \mathrm{~g}$ of elemental calcium daily (calcium lactate gluconate, Sandoz), or calcium alone.

Twenty two patients were allocated to each treatment group. The patients visited the outpatient clinic every four weeks. Periodically, if the patient was clinically stable according to clinical symptoms and spirometric results, the dose of prednisone was tapered down by $2.5 \mathrm{mg}$. When clinical deterioration occurred oral corticosteroid treatment was intensified

Re author

Revised version received

22 February 1994

Accepted for publication

1 August 1994 
Table 1 Mean (SD) patient data

\begin{tabular}{|c|c|c|c|c|}
\hline & \multicolumn{2}{|c|}{12 months follow up } & \multicolumn{2}{|c|}{24 months follow up } \\
\hline & $\begin{array}{l}\text { sCT-NS group } \\
(n=22)\end{array}$ & $\begin{array}{l}\text { Calcium group } \\
(n=22)\end{array}$ & $\begin{array}{l}\text { sCT-NS group } \\
(n=17)\end{array}$ & $\begin{array}{l}\text { Calcium group } \\
(n=17)\end{array}$ \\
\hline $\begin{array}{l}\text { M:F } \\
\text { Age (years) } \\
\text { Average glucocorticoid dose }\end{array}$ & $\begin{array}{l}3: 19 \\
58.9(7 \cdot 6)\end{array}$ & $\begin{array}{c}3: 19 \\
58 \cdot 8(6 \cdot 3)\end{array}$ & $\begin{array}{c}3: 14 \\
58^{(6 \cdot 6)}\end{array}$ & $\begin{array}{c}3: 14 \\
57^{(9 \cdot 1)}\end{array}$ \\
\hline $\begin{array}{l}\text { (mg prednisone/day) } \\
\text { Duration of steroid treatment (years) } \\
\text { Aerosol steroid dose ( } \mu \mathrm{g} / \text { day) }\end{array}$ & $\begin{array}{c}10(4 \cdot 2) \\
9 \cdot 7(6 \cdot 7) \\
1472(590)\end{array}$ & $\begin{array}{r}10.5(4 \cdot 5) \\
11 \cdot 6(8 \cdot 4) \\
1193(764)\end{array}$ & $\begin{array}{r}10 \cdot 6(4 \cdot 4) \\
9 \cdot 1(5 \cdot 2) \\
1193(764)\end{array}$ & $\begin{array}{r}10 \cdot 8(4 \cdot 4) \\
11 \cdot 8(8 \cdot 4) \\
1285(761)\end{array}$ \\
\hline
\end{tabular}

sCT-NS = salmon calcitonin nasal spray.

(prednisone $30 \mathrm{mg} /$ day tapered down by $5 \mathrm{mg}$ / day every three days). Inhaled steroids (budesonide or beclomethasone) were given to all patients.

All patients gave informed consent to participate in the study which was approved by the hospital research committee.

\section{BONE MINERAL MASS}

The bone mineral density (BMD) was determined by means of dual photon absorption measurement on L2 to L4 at the beginning of the study and at one and two years (Lunar Radiation Corporation Scanner DP3, Madison, Wisconsin, USA) and expressed in terms of $\mathrm{g} / \mathrm{cm}^{2}$. The coefficient of variation in vitro, calculated with daily phantom studies $(\mathbf{n}=$ 300 ) collected over one year, was $0.51 \%$. The coefficient of variation in vivo was $1.37 \%$ in healthy young subjects and $2 \cdot 7 \%$ in patients with osteoporosis. These data were obtained from 10 normal volunteers and five osteoporotic patients measured weekly for five weeks. Predicted BMD values were obtained from 547 healthy women and 328 healthy men (unpublished data).

\section{RADIOLOGICAL STUDY}

Radiographs of the thoracic and lumbar spine in two projections were obtained before entry to the study and at the end of the follow up period. Deformities of vertebral bodies were divided into two groups: wedge and crush fractures. Wedge fractures were defined as a reduction of $25 \%$ or more in the anterior height of the vertebrae; a crush fracture was diagnosed when the posterior height of the vertebra was less than $25 \%$ of the posterior height of an adjacent vertebra. Radiological evaluation was performed by a blinded experienced observer. Symptomatic fractures from other bones (ribs, femurs) were also recorded.

\section{LABORATORY STUDIES}

Serum and urine biochemical measurements were performed at baseline, one year, and two years. Serum and urine levels of calcium, phosphate and creatinine levels were measured by routine methods using an autoanalyser. Serum osteocalcin levels (bone Gla-protein) were measured by radioimmunoassay. Urine hydroxyproline levels were measured colorimetrically after fractioning by high pressure liquid chromatography.

\section{DATA ANALYSIS}

Changes in BMD and biochemical indices during the follow up period were analysed by one way analysis of variance (ANOVA) and Sheffe's contrasts. Differences in these parameters between the calcitonin group and the control group were analysed by a non-parametric test (Mann-Whitney $U$ test). A probability value of 0.05 was considered significant. Bonferroni's adjustment $(0.05 / \mathrm{n}$ tests $)$ for multiple testing was used to prevent a type I error.

\section{Results}

The first year of follow up was completed by all participants. During the second year of the study there were five dropouts in the calcitonin group and five in the calcium alone group. One patient was withdrawn from the calcitonin group due to the development of a generalised pruritus. Four and five patients from the calcitonin and calcium alone groups respectively were withdrawn because, due to a progressive stabilisation of asthma, they could be removed from oral glucocorticoid treatment. Table 1 summarises the characteristics of the subjects and their glucocorticoid treatment upon entry into the study. Four patients in each group had suffered bone fractures before entering the clinical trial.

Tables 2 and 3 show the average changes in anti-asthmatic treatment (oral and inhaled steroids) in the patients who completed one and two years of treatment. There was a similar and significant decrease in oral steroid doses in both groups during the study. Before the study the calcium alone group was on significantly lower doses of inhaled steroids. However, inhaled steroid dosage rose during the study and both groups received similar doses of these drugs throughout the two years.

Table 4 gives the biochemical parameter values at one year of follow up. Similar results were seen at two years. No significant changes were detected in the biochemical parameters over the two year treatment period.

The mean (SD) baseline value of BMD expressed as percentage predicted was $87 \cdot 8(12)$ for the calcitonin group and 91(11) for the calcium alone group; this difference was not statistically significant. The serial measurements of the bone mineral mass of the lumbar spine over the two years are shown in the figure. The bone mass in the calcitonin group increased by $2 \cdot 7 \%$ during the first year while in the group receiving calcium alone it decreased by $2 \cdot 8 \%(p<0 \cdot 005)$ Calcitonin prevented more bone loss during the second 
Table 2 Mean (SD) changes in steroid doses at entry to the study and at 12 months

\begin{tabular}{|c|c|c|c|c|}
\hline \multirow{2}{*}{ (2. } & \multicolumn{2}{|l|}{ sCT-NS group } & \multicolumn{2}{|l|}{ Calcium group } \\
\hline & Baseline & 12 months & Baseline & 12 months \\
\hline $\begin{array}{l}\text { Average glucocorticoid doses } \\
\text { (mg prednisone/day) }\end{array}$ & $10(4 \cdot 3)^{*}$ & $7.9(3.9)^{*}$ & $10 \cdot 5(4 \cdot 5)^{* *}$ & $7 \cdot 5(4 \cdot 5)^{* *}$ \\
\hline $\begin{array}{l}\text { Aerosol glucocorticoid doses } \\
(\mu \mathrm{g} / \mathrm{day})\end{array}$ & $1472(590)$ & $1647(586)$ & 1193 & 1518 \\
\hline
\end{tabular}

sCT-NS $=$ salmon calcitonin nasal spray.

${ }^{*} \mathrm{p} \leqslant 0.03 ;{ }^{* *} \mathrm{p} \leqslant 0.01$.

Table 3 Mean (SD) changes in steroid doses at entry to the study and at 24 months

\begin{tabular}{lccccc}
\hline & \multicolumn{1}{c}{$s C T-N S$ group } & & & \multicolumn{2}{c}{ Calcium group } \\
\cline { 2 - 3 } & Baseline & 24 months & & Baseline & 24 months \\
\hline $\begin{array}{c}\text { Average glucocorticoid doses } \\
\text { (mg prednisone/day) }\end{array}$ & $10 \cdot 6(4 \cdot 6)$ & $7 \cdot 7(5 \cdot 5)$ & & $10 \cdot 8(4 \cdot 4)^{*}$ & $7 \cdot 8(5 \cdot 2)^{*}$ \\
$\begin{array}{c}\text { Aerosol glucocorticoid doses } \\
(\mu g / \text { day) }\end{array}$ & $1411(597)$ & $1729(604)$ & & $1285(761)$ & $1635(762)$ \\
\hline
\end{tabular}

sCT-NS = salmon calcitonin nasal spray. ${ }^{*} \mathrm{p} \leqslant 0.01$.

Table 4 Mean (SD) biochemical parameters at entry to the study and at 12 months

\begin{tabular}{|c|c|c|c|c|}
\hline & \multicolumn{2}{|l|}{ Calcium group } & \multicolumn{2}{|l|}{ sCT-NS group } \\
\hline & Baseline & 12 months & Baseline & 12 months \\
\hline $\begin{array}{l}\text { Calcium (mg/dl) } \\
\text { Phosphate (mg/dl) } \\
\text { Magnesium (mg/dl) } \\
\text { Osteocalcin (ng/ml) } \\
\text { AP (IU/l) } \\
\text { Ca/Cr ratio } \\
\text { HxP/Cr ratio }\end{array}$ & $\begin{array}{l}9.7(0.4) \\
3.4(0.5) \\
1.9(0.2) \\
7.3(2) \\
151(54) \\
0.168(0.11) \\
107(35)\end{array}$ & $\begin{array}{l}9.9(0.5) \\
3 \cdot 4(0 \cdot 4) \\
2(0 \cdot 1) \\
9 \cdot 6(3 \cdot 5) \\
174(64) \\
0 \cdot 187(0 \cdot 11) \\
116(52)\end{array}$ & $\begin{array}{l}9 \cdot 7(0.5) \\
3 \cdot 5(0 \cdot 4) \\
2 \cdot 2(0.4) \\
7 \cdot 5(2 \cdot 5) \\
165(53) \\
0 \cdot 161(0 \cdot 11) \\
155(75)\end{array}$ & $\begin{array}{c}9 \cdot 9(0 \cdot 4) \\
3 \cdot 4(0 \cdot 5) \\
2(0 \cdot 2) \\
9 \cdot 5(4 \cdot 3) \\
185(62) \\
0.217(0 \cdot 13) \\
100(29)\end{array}$ \\
\hline
\end{tabular}

sCT-NS = salmon calcitonin nasal spray; $\mathrm{AP}=$ alkaline phosphatase; $\mathrm{Ca} / \mathrm{Cr}=$ calcium creatinine ratio; $\mathrm{HxP} / \mathrm{Cr}=\mathrm{hydroxyproline}$ creatinine ratio.

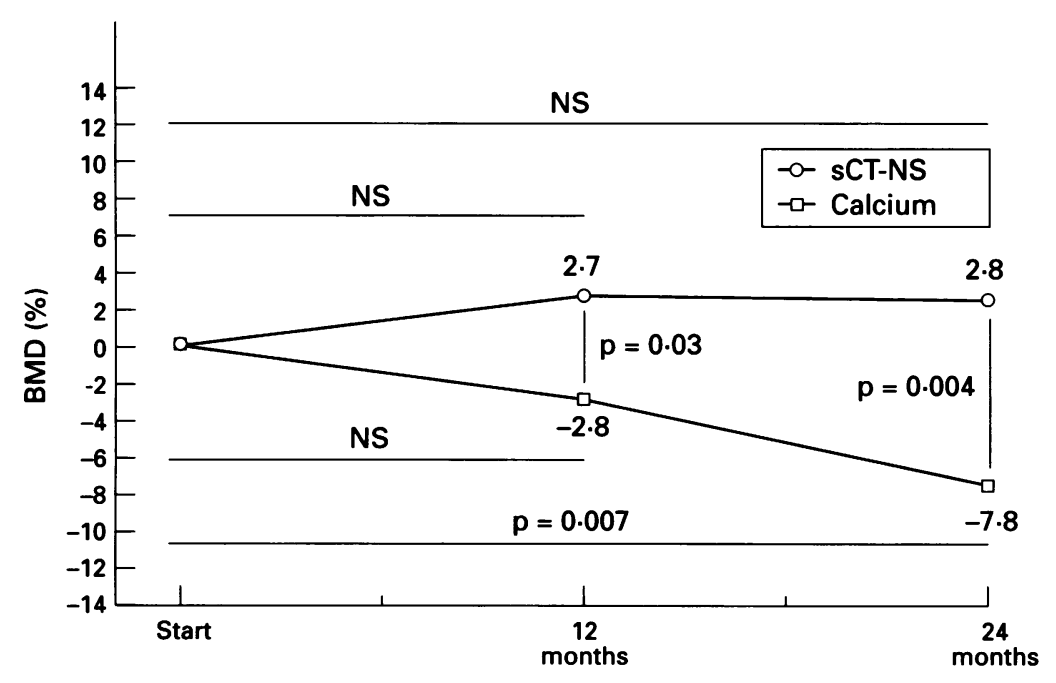

Evolution of lumbar bone mineral density (BMD) during a two year course of salmon calcitonin nasal spray (sCT-NS) 200 IU every other day $+1000 \mathrm{mg}$ calcium versus calcium alone. BMD increased in the first year of treatment with calcitonin and remained almost stable during the second. The control group lost bone mass in the first year and this continued and became statistically significant at the end of the second year. The evolution of bone mass was statistically different between both groups at one and two years.

Table 5 New bone fractures

\begin{tabular}{rllll}
\hline $\begin{array}{l}\text { Patient } \\
\text { no. }\end{array}$ & $\begin{array}{l}\text { Previous } \\
\text { fractures }\end{array}$ & $\begin{array}{l}\text { New } \\
\text { fractures }\end{array}$ & $\begin{array}{l}\text { Months of } \\
\text { treatment }\end{array}$ & Treatment \\
\hline 4 & Yes & T5 & 18 & sCT-NS+Ca \\
6 & Yes & No & & sCT-NS+Ca \\
10 & Yes & No & & sCT-NS+Ca \\
20 & Yes & No & 20 & sCT-NS+Ca \\
7 & No & Sternal & 20 & SCT-NS + Ca \\
19 & No & T7, T10, L1 & 2 & Ca \\
15 & Yes & L1, L5 & 8 & Ca \\
26 & Yes & T9, T10, T12 & 12 & Ca \\
53 & Yes & No & & Ca \\
43 & Yes & No & 13 & \\
40 & No & Femoral & 13 & \\
\hline
\end{tabular}

sCT-NS + Ca = salmon calcitonin nasal spray plus calcium; $\mathrm{Ca}=$ calcium only. year while patients in the calcium alone group continued to lose bone mass $(-7 \cdot 8 \%$ $\mathrm{p}<0.005)$

Table 5 shows the patients with fractures before entry into the study and those who developed new fractures during the follow up period. In the calcitonin group three patients developed bone fractures (two crush vertebral fractures and one sternal fracture). There were also three new fractures in the group receiving calcium alone (two crush vertebral fractures and one femoral fracture). New fractures appeared in three patients who had suffered fractures before entering the study.

Side effects during calcitonin treatment were mild. Rhinorrhea (two patients), nausea and rhinorrhea (one patient), nausea and headache (one patient), nausea alone (two patients), and facial redness (two patients) were the side effects recorded. One patient in the calcitonin group who developed a generalised pruritus was the only patient to be dropped from the study because of side effects.

\section{Discussion}

Nasal calcitonin treatment had beneficial effects on bone mineral density in glucocorticoid-dependent asthmatic patients. In the lumbar spine bone mineral density increased after one year of treatment and remained stable during the second year of treatment. These changes represent a reversal of the progressive decrease of bone mineral density in patients on placebo treatment. This result suggests that the gain in bone mass after administration of calcitonin is transient, prob- 
ably because a new steady state is reached after the initial period of treatment characterised by a decrease in bone resorption coupled by a decrease in bone formation.

Four patients from the calcitonin group and five patients from the control group were withdrawn during the second year of follow up because they lost their dependence on steroid treatment. This is not surprising since it has been shown in many studies that steroid-dependent asthmatics who regularly attended the outpatient clinic are able to be completely removed from oral steroids. A better compliance with the treatment, especially with inhaled corticosteroids, probably accounts for this finding.

The effects of prolonged treatment with calcitonin are not known. Since the slower turnover associated with antiresorptive treatment may lengthen the time expended in replacing bone tissue, the possibility that prolonged antiresorptive treatment can decrease the strength of bones must not be overlooked. ${ }^{7}$

No serious side effects attributable to calcitonin treatment occurred during the trial and only one patient dropped out of the study as a consequence of a generalised pruritus. Since this symptom did not completely disappear after discontinuing the treatment it is not clear whether the skin reaction was actually caused by calcitonin.

The effects on bone mass obtained with the nasal formulation at one year were less than those observed with the injectable presentation in our previous study $(2.7 \%$ increase in the BMD with the spray $v 4 \%$ with the injection). ${ }^{5}$ Although it is considered that the dose of 200 IU calcitonin administered by the nasal route is equivalent to $100 \mathrm{IU}$ given by the parenteral route, the bioavailability of the nasal formulation is probably less than with the injectable preparation. This might explain the minor effect of the nasal spray on bone mineral density. This lower dose might at least in part also account for the better tolerability of the nasal preparation. Since most of the asthmatic patients suffered from rhinitis of variable severity, it is possible that the presence of a chronic inflammatory process in the nose might have interfered with calcitonin absorption thereby aifecting the biodegradability of the drug.

Although calcitonin treatment prevents bone mass loss, no differences in the incidence of bone fractures could be detected. Most of the asthmatic patients included in the study had been on steroid treatment for several years. Since corticosteroid-induced bone loss appears to be most marked during the first 12 months of treatment, it could be argued that preventive treatment should start at the same time as the steroid treatment. This approach has been used by Sambrook et al in a recent study including patients with different rheumatic and immunological diseases. In these patients preventive treatment was initiated at the same time as steroids. This approach can hardly be applied to bronchial asthma, however, because it is almost impossible to predict which patient will require prolonged oral treatment when initially seen. Many asthmatic patients must be treated with oral steroids for varying periods of time before becoming clinically stabilised with the use of other drugs such as inhaled steroids. More than six months are usually needed to decide that the patient is definitely dependent on the oral steroid therapy, by which time the period of rapid effect of steroids on bone mass has already taken place. Moreover, for the practising physician the most common dilemma is how to slow down the progression of bone loss and prevent fractures in patients who have been on steroid treatment for many years and suffer a moderate or marked osteopenia, sometimes accompanied by bone fractures. In a group of such patients we have shown that intranasal salmon calcitonin at a dose of 200 IU on alternate days for two years is able to significantly decrease the magnitude of bone loss in the spine in glucocorticoid-dependent asthma. The lack of side effects of the nasal spray of calcitonin should permit the use of the hormone in prolonged treatment. However, the lack of effect on the rate of fractures precludes considering nasal calcitonin as a routine treatment to prevent steroid-induced osteoporosis. More patients followed for a longer period of time would be needed to determine whether calcitonin decreases the rate of bone fractures in addition to increasing BMD.

1 Reid IR. Pathogenesis and treatment of steroid osteoporosis. Clin Endocrinol 1989;69:83-103.

2 Godschalk M, Levy JR, Downs RW. Glucocorticoids decrease vitamin $D$ receptor number and gene expression in human osteosarcoma cells. $\mathcal{f}$ Bone Min Res 1992;7:21-7.

3 Adami S, Fossaluzza V, Rossini M, Bertoldo F, Gatti D Zamberlan $\mathrm{N}$, et al. The prevention of corticosteroidinduced osteoporosis with nandrolone decanoate. Bone Mineral 1991;15:72-81.

4 Reid IR, Alexander CJ, King AR, Ibbertson HK. Prevention of steroid-induced osteoporosis with (3-amino-1-hydroxypropylidene)-1,1-bisphosphonate (APD). Lancet 1988; propylide.

5 Luengo M, Picado C, Del Rio L, Guañabens N, Montserrat JM, Setoain J. Treatment of steroid-induced osteopenia with calcitonin in corticosteroid-dependent asthma. Am wev Respir Dis 1990;142:104-7.

6 Overgaard K, Hansen MA, Jensen SB, Christiansen C. Effect of salcatonin given intranasally on bone mass and fracture rates in established osteoporosis: a dose-response study. $B M \Im$ 1992;305:556-61.

7 Turner CH. Towards a cure for osteoporosis: reversal of excessive bone fragility. Osteoporosis Int 1991;2:12-19.

8 Sambrook Ph, Birmingham J, Kelly P, Kempler S, Nguyen T, Pocock N, et al. Prevention of corticosteroid osteoporosis. A comparison of calcium, calcitrol and calcitonin. $N$ Engl $f$ Med 1993;328:1747-52. 